\title{
NOVAS TECNOLOGIAS E NOVOS VÍNCULOS FAMILIARES: REPERCUSSÕES NO PROCESSO DE SOCIALIZAÇÃO
}

\author{
NEW TECHNOLOGIES AND NEW BONDS FAMILY: \\ REPERCUSSIONS IN THE PROCESS OF SOCIALIZATION
}

\begin{abstract}
Maura Espinheira Avena*, Elaine Pedreira Rabinovich**
Autora para correspondência: Maura Espinheira Avena - mauravena@bol.com.br

*Assistente Social, Especialista em Psicologia Social Pichoniana (CIEG/Escola Baiana de medicina e saúde), Mestre em Família na Sociedade Contemporânea (UCSAL) e Doutoranda do Programa de Pós-Graduação em Família na Sociedade Contemporânea (UCSAL)

**Psicóloga, professora do Programa de Pós-Graduação em Família na Sociedade Contemporânea (UCSAL)
\end{abstract}

\section{R E S U M O}

O presente artigo visa discutir sobre as novas tecnologias e sua influência no processo de vinculação familiar como também no processo de socialização, considerando que a família é responsável pela sustentação dos processos subjetivos e pelas funçães de educação e socialização. Foram realizadas entrevistas individuais semi-estruturadas com três casais com filhos de 5 a 10 anos. Também foi desenvolvido um trabalho de grupo operativo com as mulheres/mães entrevistadas. Observou-se que as funções de socialização e educação no grupo familiar vêm sendo dificultadas cotidianamente, como também a função parental que as sustenta, devido às condições novas e adversas que emergem com os processos sociais, culturais e tecnológicos na atualidade. Esses processos, pelo grau de aceleração com que ocorrem e se modificam, geram instabilidade e insegurança no âmbito familiar e, portanto, em seus vínculos. Neste contexto e em relação às funções já citadas, a mãe/mulher tem o papel mais participativo junto aos filhos e na sustentação dos vínculos familiares. Registrou-se ainda uma abertura na interação/comunicação entre homens e mulheres (relação conjugal) e, sobretudo, entre pais e filhos, como também a valorização de um permanente diálogo e negociação nesses vínculos. Como conclusão verifica-se a necessidade do desenvolvimento da função parental para garantir à família a reprodução de vínculos de pertencimento e superação das adversidades cotidianas.

Palavras-chaves: Vínculo familiar; novas tecnologias; socialização; contemporaneidade. 
This article aims to discuss new technologies and their influence on family bonding process as well as the socialization process, considering that family is responsible for the support of the subjective processes and the education and socialization functions. Individual semi-structured interviews were conducted with three couples with children of 05-10 years. It was also developed an operating group working with women / mothers interviewed. It was observed that the socialization and education roles in the family group have been hampered daily, as well as the parental function that sustains due to new and adverse conditions that emerged with the social, cultural and technological today. These processes, their degree of acceleration, generate instability and insecurity in the family and, therefore, into their ties. In this context and in relation to the aforementioned functions, the mother / woman has a more participatory role with the children and support of their family bonds. It was recorded also an opening in interaction / communication between men and women (married relationship) and especially between parents and children and especially between parents and children, as well as the promotion of a permanent dialogue and negotiation those bonds. As a conclusion we point out the need to develop parental function to ensure the family the reproduction of belonging links and to overcome the everyday adversities.

Key words: Family bond; new technology; socialization; contemporary. 


\section{INTRODUÇÃO}

Este artigo se originou de um estudo que buscou investigar a dinâmica interna do grupo familiar contemporâneo - rede vincular e interacional inserido no contexto de transformações sociais e tecnológicas, e sua ressonância no processo de socialização dos filhos. O marco teórico de base utilizado foi o ECRO (Esquema Conceitual Referencial e Operativo) da Psicologia Social de Pichon-Rivière, Ana Pampliega de Quiroga e alguns pensadores da Escola de Psicologia Social de Buenos Aires/Argentina. A este eixo central se articularam, dialogando permanentemente, outros aportes teóricos como a Sociologia, a Sociologia da família e a Psicologia, mais especificamente a terapia sistêmica familiar, tendo em vista a complexidade do objeto e objetivos do estudo.

Pretendemos discutir as mudanças que ocorrem no processo de vinculação familiar, a partir da vida cotidiana atual, como também seus reflexos no processo de socialização, considerando que, mesmo com todas as transformações em curso, é a família que assume a responsabilidade não só de cuidar e proteger, mas fundamentalmente de transmitir os ensinamentos e educar os filhos, tarefa esta que tem relação com o modo com o qual a família vivencia e repassa a cultura ora vigente.

O papel da família como organização que cuida, protege, humaniza e estrutura o indivíduo, por meio do afeto e da educação, e que possibilita uma transição saudável deste para "o mundo maior", ou seja, a comunidade da qual ele faz parte, obriganos a repensar sobre as novas tecnologias, os "novos" vínculos familiares e a repercussão destes na tarefa de socialização. Neste contexto no qual a educação deixou de ser monopólio da família e da escola e onde a informação se dá através de vários agentes e de maneira rápida, quais são os desafios que a família vem enfrentando para educar e transmitir valores? A família vem conseguindo manter seus vínculos de pertença, enquanto grupo, e sustentar seu papel social de formar indivíduos para viverem em sociedade? Que sujeito está sendo formado no contexto familiar e social, marcado por diversos fenômenos tecnológicos e culturais?

É evidente que o estudo realizado não teve a pretensão de responder todas estas perguntas, mas objetivou trazer à tona alguns pontos de discussão e análise fundamentais para nortear outras possíveis pesquisas.

\section{A FAMÍLIA NO CONTEXTO DO CONSUMO E DA TECNOLOGIA}

A família, como instituição, está situada em um tempo histórico determinado e, nesse contexto de transformações não poderia deixar de sofrer diversas consequências. Tais consequências podem ser vistas inicialmente a partir das várias configurações através das quais a família vem se mostrando, o que implica em mudanças nos vínculos entre seus membros e novas formas de significado em relação aos papéis adotados, como também em relação à vida cotidiana da sociedade na qual está inserida. Conforme Petrini e Cavalcanti ${ }^{1}$ :

Trata-se de mudanças profundas e permanentes, que dizem respeito à atividade produtiva e à organização do trabalho, aos processos educativos e de comunicação, até a socialização das novas gerações, ao universo de valores e critérios que orientam a conduta no quotidiano.

Essas mudanças, concentradas e aceleradas, repercutem significativamente na vida familiar, desde a concepção de masculinidade e feminilidade e a forma de compreender a sexualidade e a relação entre os sexos, até a maternidade e a paternidade, a relação entre as gerações, principalmente

no tocante à atividade educativa e de socialização'.

Seria desnecessário realizar um caminho pela história da família e suas várias expressões de acordo com cada época e sua específica cotidianidade. No momento, vale mais ratificar a complexidade dos processos sociais atuais e os desafios pelos quais a família passov e ainda vem passando, como também refletir sobre algumas repercussões na rede familiar e em suas funções, considerando a sociedade do consumo e da tecnologia. Nas palavras de Quiroga ${ }^{2}$.

A família é um complexo campo de forças no qual se interpenetram fenômenos tão distintos como os processos intrapsíquicos dos indivíduos que o integram e os aspectos mais amplos da cultura e os interesses sociais ${ }^{2}$.

Diante de um contexto tão complexo, surgem muitos questionamentos em relação aos papéis, funções, 
direitos e deveres familiares, até por conta da impossibilidade de uma identificação com um modelo único e ideal de família. Por outro lado, não temos a pretensão de apontar aqui o "melhor" arranjo familiar e a maneira "mais eficaz" de desenvolver suas funções de educar e socializar e, portanto, o grupo familiar "mais adequado" para que a criança se desenvolva física, psíquica e socialmente. Mas entendemos que é preciso considerar e ressaltar que a família, como "grupo de pertença", sempre teve e continuará tendo uma importância fundamental para o indivíduo e para a sociedade, no sentido de que é ela quem estrutura o sujeito e a subjetividade através do processo de socialização, dando-lhe as condições básicas de sobrevivência e fazendo com que o mesmo possa se transformar em um indivíduo capaz de viver socialmente e de contribuir para 0 desenvolvimento da comunidade onde vive.

A expressão "grupo de pertença" está relacionada ao conceito de "pertença" utilizado pelo ECRO (Esquema Conceitual Referencial e Operativo) da Psicologia Social de Pichon-Rivière ${ }^{3,4}$ para resgatar a importância do processo de vinculação no grupo familiar. Neste processo interacional não predominam os interesses individuais sobre os do grupo, o que não significa dizer que as diferenças pessoais não sejam respeitadas; mas o que se busca de modo geral é a satisfação do grupo como um todo, cada um desenvolvendo seus respectivos papéis e tarefas. Pode haver competitividade, mas esta não é maior que a cooperação entre eles, pois há um significado comum a todos do sentido do grupo e em seu sentimento de pertencimento. Os integrantes deste grupo se sentem co-partícipes e, portanto, coresponsáveis pelos sucessos e insucessos do grupo. Com isso não estamos afirmando que este grupo, ao construir este sentimento de pertença, deixe de ter dificuldades e que viva em perfeita harmonia, mas pontuando que ele está mais integrado e mais fortalecido em sua relação vincular para sustentarse em suas funções e reproduzir-se enquanto um recurso para a pessoa e para a sociedade.

A família responde a necessidades humanas e sociais relevantes, por isso é considerada um recurso para a pessoa e para a sociedade. Muitos estudiosos observam que a estrutura familiar permanece, sob uma multiplicidade de formas, nas diversas culturas, em todos os períodos históricos, como forma de relação social constitutiva da espécie humana. (...) Em suma, a família é um requisito do processo de humanização, que enraíza a pessoa no tempo, através das relações de parentesco, destinada a permanecer durante toda a existência ${ }^{5}$.

A garantia da reprodução da lógica de mercado e de consumo, como também da informação desenfreada e do individualismo é o que se vê hoje em quase todas as instâncias sociais. Mesmo se constituindo enquanto grupo de pertença, sustentando seus vínculos de pertencimento e sendo valorizada como um recurso para a pessoa e para a sociedade, a família não foge totalmente a essa lógica, ainda que possa ultrapassá-la e buscar reproduzir-se em sua dimensão diferenciada no que diz respeito aos processos de vinculação e subjetivação tão fundamentais à formação da pessoa.

Vivemos na era da tecnologia, da efemeridade ${ }^{6} \mathrm{e}$ da liquidez ${ }^{7}$ e estas estão submetidas à lógica do consumo e do mercado. Tudo é possível de consumir e tudo muda o tempo todo no mundo, mesmo os vínculos que estabelecemos com os outros que "a priori" deveriam ser duradouros. Também os vínculos são tratados como mercadorias e produtos ou até mesmo objetos que podem ser a qualquer tempo substituídos, ainda que não haja nenhuma garantia em relação ao novo produto ou nova relação. Nessa lógica $\circ$ afeto e o sentimento de pertencimento de uma relação ou de um grupo seriam substituídos pelos "relacionamentos de bolso", fragilizados e esvaziados de humanidade, porém muito mais funcionais a lógica instituída pela cultura utilitarista. Perguntamo-nos a partir deste ponto de vista se a família não estaria sendo contemplada meramente como um agrupamento de funções que objetiva dar as condições de sobrevivência para o sujeito, como também satisfazer-lhe nas necessidades impostas pela cultura consumista. Não obstante, não se constituiria como um "grupo de pertença" e não se assumiria, de fato, sua função primordial de socializar, mas só de maneira idealizada.

O estudo de A. C. T. Ribeiro e I. Ribeiro ${ }^{8}$, citado no texto a "fragilização das funções parentais na família contemporânea: determinantes e consequências", pontua a seguinte colocação:

... os novos valores da família estruturam-se em torno do caráter idealizado de cuidados, de respeitos à autonomia e às individualidades, e conjectura-se que essas foram as formas em que "individualismo". "igualdade de direitos" e "narcisismo" têm-se apresentado na família. Essas mudanças podem ser entendidas como efeito de uma sociedade pouco 
compromissada com o próximo que, refletida na família, assume esse caráter de "emergência de cuidados", mas que efetivamente não ocorre, porque se os pais estão tomados pelo ideal, na prática, não se implicam nesta tarefa de educar ${ }^{8}$.

Desde este ponto de vista e a partir do nosso estudo, consideramos este $\circ$ grande desafio da família contemporânea: diante da lógica ora vigente, manter-se em seus vínculos de pertencimento e em sua função de sustentação dos processos subjetivos e, portanto, fortalecendo-se em sua função parental responsável pela socialização e educação dos indivíduos.

A tecnologia e seus diversos recursos como também a informação poderão se constituir em um ator coadjuvante nesse processo, caso a família disponha ou busque os conhecimentos e instrumentos necessários para manejá-los em benefício próprio, fortalecendo seus vínculos de pertencimento. Caso contrário, a família se descobrirá como "um barco à deriva" nesse percurso, e aquilo que poderia ter sido um ator coadjuvante se converterá em um maremoto que tornará a tarefa de educar e socializar um processo penoso de grandes e intransponíveis obstáculos e os aspectos negativos não serão vistos unicamente no grupo familiar, mas na comunidade da qual esta família faz parte.

\section{MÉTODOS}

O estudo desenvolvido foi de natureza qualitativa e conforme já exposto, o grupo operativo, dispositivo grupal criado pelo Dr. Enrique PichonRivière (1994) foi um dos instrumentos utilizados para abordagem e investigação. A razão da escolha do mesmo está relacionada a dois aspectos que consideramos importantes: 0 primeiro é que acreditamos que em qualquer estudo, o método ou os procedimentos metodológicos utilizados não estão separados dos aportes teóricos que sustentam - trabalho e, por esta razão, há uma coerência epistemológica ao utilizarmos o grupo operativo estando este sustentado pela teoria que sempre o sustentou e deu significado: o ECRO da Psicologia Social. O segundo, devido ao fato da importância da abordagem da problemática inserida em um espaço grupal concreto, identificando-se a rede vincular deste âmbito.

O ECRO, através do grupo operativo, pôde ser utilizado como instrumento de apreensão, interpretação e leitura da realidade e através dele e de seu enquadre a pesquisadora desenvolveu o papel de coordenadora do grupo, contando com sua 'atitude psicológica' para intervir no campo grupal e, é claro, com o suporte de alguns aparelhos tecnológicos (gravador) para fazer o registro das colocações dos integrantes. Objetivado visualizar e compreender como se reatualiza no grupo o processo dinâmico vincular, o grupo operativo pôde promover discussões, confirmando o colocado por PichonRivière, quando afirma que ele traduz e reflete aspectos do mundo cotidiano problematizando-os.

O grupo operativo é a primeira instância de ancoragem do cotidiano. As relações cotidianas, os vínculos que põem em jogo modelos internos tendem a reproduzir-se nele. $O$ enquadramento ou a técnica operativa do grupo (conjunto de constantes metodológicas que permitem a compreensão de um processo), através da confrontação desses modelos internos numa nova situação de interação, e na análise de suas condições de produção, facilitam a compreensão dos modelos sociais internalizados que geram e organizam as

formas observáveis de interação ${ }^{3}$.

Desde esse ponto de vista e, se o indivíduo, para Pichon-Riviére, em certas circunstâncias conscientes ou inconscientes, é considerado como porta-voz do grupo ao qual pertence, o grupo, por sua vez, pode ser considerado como um porta-voz de situações sociais. É na cena grupal que emergem e podem ser problematizados os sentimentos, conflitos, expectativas e desejos que não poderiam ser expressos em outros tipos de abordagens. Por esta razão entendemos que o grupo operativo é um potente instrumento de aprendizagem e pesquisa.

\section{PROCEDIMENTOS METODOLÓGICOS}

O caminho percorrido para chegar à informação e ao conhecimento foi delineado pelos momentos do planejamento de uma ação propostos por PichonRivière: Estratégia, Tática, Técnica e Logística. A estratégia utilizada esteve voltada para a complementaridade de instrumentos utilizados, a saber: o roteiro geral de questões norteadoras, elaborado com base no problema a ser investigado e nos objetivos da pesquisa; o roteiro 
semiestruturado de entrevista e o grupo operativo como dispositivo para acessar o campo grupal familiar. Na prática esta estratégia converteu-se em tática e os elementos necessários ao estudo foram sendo ajustados (logística).

Quanto aos aspectos éticos, o estudo seguiu as Diretrizes e Normas Regulamentadoras de Pesquisas Envolvendo Seres Humanos do Comitê de Ética em Pesquisa e todos os participantes conheceram seus propósitos, objetivos e procedimentos e concordaram com os mesmos assinando o Termo de Consentimento Livre e Esclarecido (TCLE).

Em relação as entrevistas os casais foram recrutados em uma escola que atende a uma clientela de classe média de Salvador e foram escolhidos através da faixa etária de seus filhos e, portanto, ano letivo. Antes foi devidamente solicitada a autorização da instituição para a realização das entrevistas, sendo estas em seu próprio espaço para facilitar o acesso aos pais. As três entrevistas foram realizadas de forma individualizada seguindo o referido roteiro e a partir da aprovação do comitê de ética em pesquisa. Em seguida, com a estratégia de não apenas complementar a informação, mas, fundamentalmente, de abrir a possibilidade da abordagem do campo interacional/grupal, foi desenvolvido o grupo operativo com as três mulheres/mães cônjuges dos casais entrevistados e mais duas mulheres cujos cônjuges não puderam ser entrevistados. Além de complementar e/ou ratificar os elementos coletados, este instrumento permitiu acessar as possíveis dinâmicas interacionais que surgem em um grupo familiar, tendo em vista que seu funcionamento se dá através da comunicação e vinculação em função de suas necessidades/tarefas, como acontece na família em função do processo de socialização/educação do (s) filho (s).

Houve então um contato pessoal com as mulheres/ mães, no qual foram explicados os propósitos e objetivos da pesquisa e marcada a entrevista com data, horário e local escolhidos pelas mesmas. Todas as entrevistas femininas que estavam previstas foram realizadas, uma delas em uma das salas de aula da Escola e duas nos respectivos locais de trabalho das mulheres/mães. Ao término de cada entrevista, a pesquisadora questionava as mulheres/mães sobre sua disponibilidade para participar do grupo operativo, combinado dia, local e horário para os encontros. Também lhes perguntava sobre a possibilidade de seus maridos (pais) de participarem da pesquisa como elas e, nessa oportunidade, solicitava que falassem para eles (os esposos) a respeito do trabalho. Finalmente explicava as mulheres/mães que faria, posteriormente, um contato com cada um para ratificar sua participação no estudo.

Os sujeitos participantes das entrevistas foram identificados como casais $A, B$ e $C$, conforme o quadro 1 abaixo.

\begin{tabular}{|c|c|c|c|c|c|}
\hline $\begin{array}{c}\text { Participantes } \\
\text { /casal }\end{array}$ & Sexo & Idade & Profissão & $\begin{array}{c}\text { Tempo/ } \\
\text { Casamento }\end{array}$ & Filhos/idade \\
\hline A & $\begin{array}{l}\text { Masculino } \\
\text { Feminino }\end{array}$ & 45 & $\begin{array}{l}\text { Contador } \\
\text { Administradora }\end{array}$ & 16 anos & $\begin{array}{l}2 \text { filhos }-7 \text { e } \\
13\end{array}$ \\
\hline B & $\begin{array}{l}\text { Masculino } \\
\text { Feminino }\end{array}$ & $\begin{array}{l}44 \\
40\end{array}$ & $\begin{array}{l}\text { Contador } \\
\text { Contadora }\end{array}$ & 12 anos & 2 filhos -8 e 9 \\
\hline C & $\begin{array}{l}\text { Masculino } \\
\text { Feminino }\end{array}$ & $\begin{array}{l}36 \\
36\end{array}$ & $\begin{array}{l}\text { Dentista } \\
\text { Dentista }\end{array}$ & 13 anos & 2 filhos -7 e 9 \\
\hline
\end{tabular}

Quadro 1. Dados sócio-demográficos dos sujeitos das entrevistas, Salvador, 2013 
Os sujeitos participantes do grupo operativo foram identificados pelo nome de "integrante" de acordo com o quadro 2 abaixo. Dessa forma foi possível delinear melhor o perfil dos sujeitos de nosso estudo.

\begin{tabular}{|c|c|c|c|c|c|}
\hline Integrante & Sexo & Idade & Profissão & $\begin{array}{c}\text { Tempo } \\
\text { /casamento }\end{array}$ & Filhos/idade \\
\hline 1 & Feminino & 38 & Contadora & 12 anos & 2 filhos - 8 e 9 \\
\hline 2 & Feminino & 41 & Administradora & 16 anos & 2 filhos- 7 e 13 \\
\hline 3 & Feminino & 36 & Dentista & 13 anos & 2 filhos -7 e 9 \\
\hline 4 & Feminino & 45 & Administradora & 22 anos & $\begin{array}{c}3 \text { filhos }-7,12 \text { e } \\
2\end{array}$ \\
\hline 5 & Feminino & 39 & Administradora & 10 anos & 2 filhos - 4 e 8 \\
\hline
\end{tabular}

Quadro 2. Dados sócio-demográficos dos sujeitos do grupo, Salvador, 2013

Também identificamos tais sujeitos de acordo com seus papéis no grupo familiar - pai e mãe; esposo e esposa - e suas colocações/falas de acordo com os cinco eixos de análise no quadro 3.

Os critérios utilizados para a escolha dos casais foram os seguintes:

- Casais de classe média/média alta de salvador/ $\mathrm{BA}$;

- Casados formalmente ou não;

- Cujos cônjuges tivessem na faixa etária entre 35

e 45 anos;

- Com um ou mais filhos, sendo pelo menos um com idade entre 5 e 10 anos;

- Com nível de escolaridade superior.

Podemos dizer que um dos motivos pelos quais escolhemos trabalhar com a classe média está relacionado ao fato de considerarmos que esta classe é detentora de um poder de reprodução social de valores, crenças e representações significativas e isto tem relação direta com a questão da educação e da socialização dos indivíduos. Muito embora seja bastante difícil mapear e definir a classe média hoje, sobretudo do ponto de vista econômico, do ponto de vista social e educativo, acreditamos que esta classe tem uma responsabilidade preponderante em relação à difusão e repasse de valores predominantes socialmente, sobretudo devido ao lugar que ocupa no processo produtivo. Outra razão da escolha desta classe é por conta da acessibilidade a uma escola de classe media de
Salvador, entendendo que o recrutamento destes participantes de modo aleatório poderia acarretar em entraves para acessá-los. Assim foi realizado o recrutamento dos casais cujos filhos estudavam no grupo 8 (entre 7 e 9 anos de idade), estando assim, na faixa etária requerida pelo estudo.

Optamos por casais mais maduros tanto na idade quanto no tempo de relação da vivência conjugal e parental, tendo em vista que assim já teriam vivenciado mais aspectos desta dinâmica interacional e teriam mais elementos para compreender e delinear melhor tal dinâmica interna no momento de suas respostas às entrevistas. Pensamos que o fato de todos serem de nível superior também poderia ser um facilitador neste sentido.

Quanto aos filhos em idade entre 5 e 10 anos, foi para que tivéssemos uma ideia mais concreta da maneira de criação e educação/socialização dos mesmos, já que nesta fase começam a aparecer as matrizes ou modelos internos que já foram formadas na fase inicial da vida. E isso está relacionado também a uma possibilidade de diálogo maior com os pais e com percepção destes de seus filhos e dos modelos que estariam sendo internalizados e ou organizados vincular e socialmente.

\section{Análise}

Para fins de análise, foram criados cinco eixos temáticos ou interpretativos com a finalidade de permitir que os elementos oriundos das entrevistas 
e do grupo fossem apresentados e analisados de modo organizado. Neste artigo escolhemos trazer para discussão o eixo que denominamos Novas tecnologias $X$ novos vínculos $X$ novos modelos de aprendizagem no grupo familiar.

\section{TECNOLOGIAS, VÍNCULOS E SOCIALIZAÇÃO NO GRUPO FAMILIAR}

... mesmo num mundo tecnológico a gente tenta fazer com que elas (as filhas) curtam a infância como nós curtimos... acho que tem que brincar de boneca, assistir programas educativos e interativos... é mais DVD infantil, tem programas que elas não assistem. (...) elas podem brincar no computador

no fim de semana, mas com a supervisão da gente, elas não têm esse negócio de facebook, essas redes porque não vemos necessidade... meu irmão deu um celular a $L$ (filha mais

velha), mas ela mal usa, deixa em casa e não leva para a escola... (Pai -Casal C)

Os emergentes que nesta fala aparecem, através do pai de uma das famílias, estão relacionados à nova ordem social, econômica e cultural e suas novas tecnologias e redes sociais e de comunicação que invadem cada vez mais e mais rápido a vida cotidiana da família, do trabalho e do tempo livre, reorganizando as formas relacionais e vinculares entre as pessoas, com o tempo e os espaços, imprimindo nestas formas um ritmo mais acelerado. A realidade social começa a se organizar (como também as suas instituições) através destes avanços tecnológicos, da internet e das redes sociais (realidade/espaço virtual), como também em termos produtivos através do aumento de serviços, ofertas e de consumo. $O$ consumo passa a ser então um elemento comum a todas as classes sociais, cada uma com seu próprio perfil e poder de compra e acesso às novas tecnologias.

... com esse tempo de modernidade e tecnologia... muita informação... acho assim que tá muito difícil criar, dar educação... como tudo está muito a mão as vezes o filho vem

e pede determinada coisa e eu falo 'não' e ele pergunta 'porque não? A mais nova questiona mesmo! (Mãe - casal B)

Em todos os grupos familiares que participaram deste trabalho, os casais manifestaram que se sentem muitas vezes "reféns" do apelo sistemático ao consumo e à informação indiscriminada. Todos falaram sobre as dificuldades de argumentação e orientação no sentido de colocar limites nos "desejos de consumo" dos filhos, não raras vezes promovidos e incentivados pelas mídias e pela convivência com outros grupos sociais. Este dado aparece como um dos grandes obstáculos enfrentados pelas famílias na atualidade em relação à socialização/educação dos filhos, juntamente com outro dado que diz respeito às dificuldades em mensurar o controle lou a falta deste) do uso de aparelhos tecnológicos, como tablets, minigames, celulares, computadores, etc., como também do acesso e uso das redes sociais.

... essa garotada de hoje infelizmente ou felizmente tem a facilidade da internet então tem muito mais informação do que nós tivemos... a informação boa é bom, mas a informação ruim não e se você não estiver ali para filtrar, a informação acaba sendo ruim para o ambiente da família... eu passo por isso; por exemplo, eu não tenho como, por mais que eu controle o acesso de meu filho mais velho a

internet, eu não tenho como ficar todos os dias olhando o computador depois que ele vai dormir para ver em que site

ele está entrando e o computador fica no quarto dele... e tem a questão da privacidade, por isso eu procuro investir em conversa e bate papo e tento trazer ele para perto". (Pai -

casal B)

... a gente procura controlar, elas não têm acesso às redes sociais, facebook, Orkut, porque achamos que é prematuro, não tem celular inclusive, para que não se comuniquem com outras pessoas que a gente não vai ter o controle... a gente acha que elas não têm idade suficiente para lidar com isso... mas é difícil. (Pai - casal A)

Tais relatos confirmam o que já citamos anteriormente em relação ao controle, ou pelo menos à tentativa de controle do acesso dos filhos à informação e às novas tecnologias, partindo do pressuposto de que as crianças necessitam de acompanhamento em seu processo de educação e socialização para que não leiam, vejam ou acessem algum tipo de informação que ainda não tenham maturidade para entender, resultando em dificuldades comportamentais e vinculares no grupo familiar. Em todas as famílias, a atitude de acompanhamento e controle nas práticas educativas e de socialização em relação a tais aspectos ficou bem visível, entretanto, fica evidente também a falta de segurança em relação às estratégias utilizadas para esse controle, ou seja, prevalece em geral o questionamento se, de fato, tais formas de controle estariam sendo eficazes, tendo em vista que o apelo excessivo e incansável das mídias, sobretudo da TV e da internet, não se encontra só em casa ou na escola, mas em vários 
lugares e locais aos quais as crianças também têm acesso, como no condomínio ou na casa de parentes e colegas, etc.

Por outro lado, e mesmo que esse emergente apareça em proporção bem menor que aquele relacionado aos limites, controle e ao receio do acesso à "má informação", a facilidade de acesso à informação com a revolução das redes sociais e da internet, apareceu como um ponto positivo no que se refere ao suporte em relação ao acompanhamento das atividades escolares.

... agora se a gente não souber a gente faz pesquisa, vai no Google...ou em algum site, já que as vezes o livro não tem todas as informações ou não tem a informação completa para ajudar nosso filho... e não dá para colocar tudo nas costas da Escola, é um trabalho em conjunto. (Mãe - casal B)

Somando-se aos obstáculos e dificuldades enfrentados na tarefa de controle e limite dos filhos nos aspectos acima relacionados, como os próprios casais entrevistados verbalizaram, está o fato de que a grande maioria das famílias de hoje não têm um cuidado maior em relação ao acompanhamento dos filhos, tendo em vista que estão muito ocupados em seus trabalhos fora de casa e, quando voltam para casa, muitas vezes ainda continuam trabalhando no computador ou respondendo e-mails.

Não foram identificados relatos nos grupos que demonstrassem alguma dificuldade entre os casais, e em seu vínculo conjugal, em relação ao uso de tecnologias, embora exista em geral um consenso de que hoje, o uso intenso dos aparelhos, sobretudo celulares e computadores, como também o acesso sem limites às redes sociais podem influenciar na relação conjugal e na maneira como o casal se vincula. Contudo, em nosso estudo, as dificuldades relacionadas a estes aspectos só foram detectadas em nosso estudo na relação entre pais e filhos e não entre os casais.

Outro dado que apareceu na voz de quase todos os entrevistados em sua leitura das famílias atuais, traz dois componentes que estariam implícitos na relação cotidiana entre pais e filhos: culpa e compensação; ou seja, já que os pais não dispõem de tempo suficiente para doá-lo aos filhos, o sentimento de culpa os faz compensar sua ausência através do consumo de bens materiais (roupas, brinquedos, jogos eletrônicos, tablets, etc.) para os mesmos, como também através do excesso de permissividade em relação as suas atitudes, inclusive em relação à utilização indiscriminada de tecnologias e o acesso a informações que ainda não estariam condizentes com sua faixa etária.

Eu vejo assim, as pessoas hoje têm uma característica dos dois, pai e mãe trabalham e tendem a dar menos atenção aos filhos, e certamente por isso procuram compensar essa

falta de atenção com bens materiais e em fazer todas as vontades dos filhos, dar tudo o que eles querem, há uma preocupação exacerbada em querer satisfazer as necessidades das crianças, quer dizer suprir essa atenção através de coisas materiais, e a gente tem tido uma preocupação nesse sentido de que atenção não é isso, mas sim qualidade e, no momento em que a gente tem oportunidade a gente tá sempre mostrando isso a elas... (Pai - casal B)

Como já colocamos em todos os grupos apareceu a preocupação com o tempo dedicado aos filhos, não só através da presença física de ambos, pai e mãe, mas também a partir do convívio diário e da transmissão dos valores que os pais trouxeram de suas famílias de origem. Eventualmente ocorrem algumas dificuldades devido ao tempo dedicado ao trabalho que podem repercutir no aprendizado dos filhos na escola.

Poderíamos nos questionar aqui quanto às matrizes de aprendizagens ou modelos internos ${ }^{9}$ que estariam sendo organizados e significados pelos filhos destes casais/grupos familiares, problematizando assim a maneira como os mesmos estariam apreendendo sua experiência de vida a partir dos vínculos aí estabelecidos - as ausências e/ou papéis não assumidos, ainda que momentaneamente. Tais matrizes ou modelos poderiam ser menos favorecedores da aprendizagem não só na família como também fora desta, como por exemplo, na escola, levando a criança a apresentar algumas dificuldades de aprendizagem. Como também matrizes ou modelos mais estereotipados, levando a uma ausência de responsabilidade ou de atenção com as próprias tarefas. Em um dos grupos, uma mãe relatou que sua filha estava errando todo o dever da escola repetidamente e que num dado momento ela percebeu que isso era para chamar sua atenção, já que ela estava ficando muito ausente de casa e a filha estava ficando carente de sua atenção.

Mesmo com muitas dificuldades e condições 
adversas impostas pelo dia a dia, não identificamos nos casais entrevistados, pais e mães, a ausência da assunção de seus papéis em relação aos filhos na medida em que os mesmos estão quase sempre balizando suas atitudes em função da tarefa de socialização e educação destes. Ainda assim, consideramos aqui um importante emergente que surgiu na fala de todos e que tem relação com a não assunção da função parental na família e, como consequência, com a possível 'terceirização' do processo de socialização e educação dos filhos que estaria então sendo delegado a terceiros como a escola, alguns parentes mais próximos ou ainda a profissionais como babás ou auxiliares.

Foi possível observar também que ainda que os pais venham buscando assumir seus papéis e funções, ficaram evidentes os obstáculos em relação a dois aspectos que podemos considerar como emergentes: a abreviação da infância, através do apelo social e sistemático das mídias e aí estaria inserida a questão da educação e orientação sexual dos filhos; e a experiência da infância que hoje já não é mais vivida como antes/antigamente.

... como você acha que eu vou educar as meninas nesse sentido, porque hoje em dia está muito difícil... eu tenho uma conhecida que trabalha no colégio $X$ e ela já pegou uma menina de 13 anos na escada fazendo sexo oral com um menino; falei 'meu Deus, como é que eu vou educar o que eu vou falar? Então tá muito difícil hoje em dia isso... fora a questão do homossexualismo também... o que eu vou dizer? Como vou explicar isso par uma menina de 7 anos?

(Integrante 3)

Não dá para deixar sem resposta, mas também não se pode antecipar as coisas... $\circ$ que $P$ (filha) ouve ela divide com a irmã, ela ainda é muito menina e eu e o pai segurando... a gente acha que pode ser mais natural... mas elas têm chegado com questões que não são para a idade delas

e ouvem na escola... essa semana uma chegou dizendo que o coleguinha $M$ chamou $F$ para transar... e aí ela perguntou para mim: 'minha mãe o que é transar? '... eu não vou explicar para ela o que é isso do jeito que é não vejo necessidade... respondi sem dar maiores detalhes...

(Integrante 1)

Estas falas mostram que as práticas educacionais estão sempre sendo postas à prova quando se trata de uma adequação aos novos moldes e estímulos relacionais da sociedade (que certamente estão relacionados à informação sem filtro) e seus contornos mutáveis e pouco delimitados. Isso pode gerar em algum momento da vida familiar uma falta de sustentação da relação do casal com sua função parental e, portanto, certa fragilidade no vínculo entre pais e filhos, gerando ansiedade e mal estar por se verem sem instrumentos ou conhecimentos eficazes para lidar com situações novas e inusitadas no dia a dia.

Nesse sentido, concordamos que a rapidez e a intensidade com que chegam as informações $e$ como se dão as práticas e relações sociais na vida cotidiana contemporânea não favorecem e muito menos fortalecem os processos educativos e de socialização desenvolvidos na família, tendo em vista que tais processos necessitam de um tempo de permanência mais duradouro e "continente" para e entre os indivíduos. Como isso é uma qualidade difícil nos tempos atuais, paira uma instabilidade e uma incerteza na família quanto à assunção desta função.

Se educação tivesse receita eu gostaria de ter uma... é muito difícil educar, às vezes você escuta fulano foi na escola defender a criança, a criança bateu, roubou... a gente julgar é muito fácil, a gente acha que educação é obrigação de pai e mãe, mas sei lá, eu procuro dar a melhor educação possível, mas será que é mesmo a melhor educação possível que eu estou dando? Às vezes você critica o pai e a mãe, não sei, mas de repente aquela educação é boa para eles... como hoje os valores estão todos do avesso... (Mãe - casal B)

Diante de algumas colocações verbalizadas nos grupos, identificamos algumas questões acerca da infância e tais questões nos levaram à seguinte reflexão: até que ponto estas crianças de classe média, que passam o dia na escola ou não, que têm outras atividades fora da escola como, por exemplo, balé, inglês e Kumon, que têm acesso ao consumo e às tecnologias e informações; que estão sendo acompanhadas pelos pais em seu processo de aprendizagem, enfim, até que ponto elas têm infância?

... a infância de hoje é diferente da infância de ontem... a que a gente teve... outro dia eu fiquei feliz da vida porque vi L (filha) pulando corda... falei "gente minha filha sabe pular corda! (Integrante 3)

... meus filhos não sabem andar de bicicleta... e ainda não aprenderam... com nove anos... são outros tempos... e a gente

fica comparando e lembro-me dos nossos pais também... porque os nossos pais também viveram uma infância maravilhosa. Meu pai conta que meus avós não tinham dinheiro para comprar e não tinha aquela coisa que tem hoje de ter todos os brinquedos... meu pai fala que o cavalinho 
dele era um pedaço de pau de vassoura... e fazia às vezes a cabeça de um cavalo de papel e vivia brincando de cavalinho... (Integrante 2)

... aonde é que hoje nossos filhos brincam? Em shopping. Que coisa né! (Integrante 5)

Mas os limites para vivenciar uma infância mais rica e com liberdade não estão unicamente no excesso de atividades fora da escola, no consumo desenfreado por brinquedos e/ou brincadeiras que as impedem de pensar e agir por si mesmas de maneira crítica e criativa, no excesso de TV ou de jogos eletrônicos, mas também estão atrelados a dois outros aspectos não menos importantes: a) A insegurança e instabilidade dos pais para deixar que seus filhos vivam de maneira mais livre e solta; e b) A preocupação com o futuro dos mesmos justificada pela grande demanda em relação ao aprendizado de novos conhecimentos e habilidades para ser admitido pelo mercado de trabalho.

...acho que toda essa preocupação... nós moramos numa cidade grande... as mães do interior pelo menos na minha infância eu não via tanto essa preocupação... não tinha essa preocupação toda... essa coisa assim 'não vai', 'não pode'; a mãe falava 'tchau pode ir'... era uma coisa mais livre... acho que hoje em dia a gente tem mais insegurança em função do mundo das coisas... (Integrante 3 )

... nós estamos num mercado de trabalho competitivo e a gente pensa "poxa não quero que meu filho sofra tanto para chegar onde eles querem chegar', então sem querer a gente acaba imprimindo muitas tarefas para eles desde pequeno já... você vai fazer kumom, balé, isso, aquilo... porque a gente sabe que lá na frente o mercado de trabalho vai cobrar... ० inglês mesmo... na escola não tem inglês... fico pensando ter tempo para levar para fazer inglês... (Integrante 2)

.... medo de deixar seu filho no play e alguém mexer... tô morando praticamente na porta da escola, uma estuda de manhã e a outra de tarde... eu com 10/11 anos eu saia de

Argoim, minha cidade, para estudar em Castro Alves, eu pegava um ônibus todos os dias na frente de minha casa e ia para Castro Alves... ia sozinha, sem pai e sem mãe, estudava e voltava nesse ônibus... a gente hoje não deixa... (Integrante 1)

\section{DISCUSSSÃO E RESULTADOS}

Foi possível observar que a família contemporânea enfrenta vários desafios para manter-se em seus vínculos de pertencimento como também para sustentar sua função de socialização, tendo em vista as novas demandas que surgem socialmente em relação à educação como também devido às rápidas e diversas informações que são difundidas através das novas tecnologias e a lógica de mercado que impõe o consumo.

Algumas dificuldades estão relacionadas aos seguintes aspectos: 0 aumento do consumo familiar que se expressa também através das constantes demandas dos filhos, o que tem estreita relação com as informações que estes vêm na TV e na internet. A abreviação da infância e o consequente ajuste nos processos a ela relacionados de educação e orientação sexual. As dificuldades de colocar limites e de controlar o uso de aparelhos eletrônicos bem como $\circ$ acesso à internet $e$ às redes sociais. $O$ excesso de atividades realizadas pelas crianças que, além de estudarem, devem articular as atividades escolares com as atividades fora da escola e, por fim, os limites impostos pela própria família, frente à insegurança gerada por situações de violência social que dificultam o caminho para uma infância mais livre e lúdica.

Sendo assim, observamos que as rotinas familiares na vida cotidiana atual estão sendo organizadas através destas práticas e formas de vínculos e relações sociais originadas pelas novas demandas tecnológicas, sociais e culturais que começam a operar no processo de ensino/aprendizagem das crianças de forma mais empobrecida no que diz respeito à reprodução dos vínculos de pertença $e$ do entendimento da família como uma estrutura relacional imprescindível para a formação dos indivíduos.

\section{CONSIDERAÇÕES FINAIS}

A família contemporânea depara-se cotidianamente com o enfrentamento da lógica imposta socialmente pela nova ordem social - lógica na qual predominam a tecnologia, a informação, o consumo e o individualismo. Esta lógica, por sua vez, bem como os caminhos que a legitimam, trava uma luta invisível com a lógica do humanitarismo, do aprender em grupo, do se colocar no lugar do outro, da pertença 
e cooperação e, portanto, do comprometimento com a formação de indivíduos mais aptos e capazes de lidar com os inúmeros desafios cotidianos.

Nesta perspectiva podemos afirmar que a família atual está em permanente mudança e mescla em seus vínculos e relações uma lógica utilitarista e individualista, na qual seus membros buscam a satisfação individual ainda que possam eventualmente contar com os outros membros do grupo; e a lógica do pertencimento e reciprocidade, na qual predominam a cooperação em prol do grupo e a valorização do sentido de família e do que se entende por 'processo de socialização'.

\section{REFERÊNCIAS}

1. Petrini JC, Cavalcanti VRS. Família, sociedade e subjetividades. Petrópolis: Vozes; 2005

2. Quiroga AP. Enfoques y perspectivas em psicología social: desarrollos a partir delpensamiento de Enrique Pichon-Rivière. Buenos Aires: Ediciones Cinco; 1997

3. Pichon-Rivière E. O processo grupal. São Paulo: Martins Fontes; 1997

4. Pichon-Rivière E. Teoria do Vínculo. São Paulo: Martins Fontes; 1986

5. Petrini JC. Pós-modernidade e família. Bauru: Edusc; 2003

6. Lipovetsky G. O império do efêmero: a moda e seu destino nas sociedades modernas. São Paulo: Companhia das Letras; 1989

7. Bauman Z. Amor líquido: sobre a fragilidade dos laços humanos. Rio de Janeiro: Jorge Zahar; 2004

8. Bauman Z. O mal estar da modernidade. Rio de Janeiro: Jorge Zahar; 1998

9. Zanetti S, Gomes I. A Fragilização das funções parentais na família contemporânea: determinantes e consequências. Temas em Psicologia Social. $2011 ; 19(2): 491-502$

10. Quiroga AP. Matrices de aprendizaje: constitucióndelsujetoenelproceso de conocimiento. 7. ed. Buenos Aires: Ediciones Cinco; 2001

11. Avena ME. Vínculo familiar contemporâneo: ressonâncias no processo de socialização [Dissertação]. Salvador: Programa de PósGraduação em Família na Sociedade Contemporânea da Universidade Católica do Salvador; 2013 